\title{
Serious Mobile Games Development. Possibilities and Challenges for Teachers
}

\author{
${ }^{1}$ Edith Lovos ${ }^{1[0000-0002-2875-0239]}$ Iván Basciano ${ }^{1[0000-0003-1059-778 X]}$ Evangelina Gil ${ }^{1[0000-0002-}$ \\ 8531-0600] and Cecilia Sanz ${ }^{20000-0002-9471-0008]}$ \\ ${ }^{1}$ Universidad Nacional de Río Negro, Sede Atlántica, Viedma, Río Negro, Argentina \\ ${ }^{2}$ III-LIDI, Facultad de Informática, Universidad Nacional de La Plata \\ ${ }^{2}$ Investigador Asociado de la Comisión de Investigaciones Científicas de la Pcia. de Bs. As \\ elovos@unrn.edu.ar, vaanbas19@gmail.com,EvaEG19@gmail.com \\ csanz@lidi.info.unlp.edu.ar
}

\begin{abstract}
The possibilities that digital games allow in a didactic proposal are not new, however, and in relation to the specific experiences of integration of digital games in teaching and learning scenarios, a limitation is observed given by the adaptability of them to specific contexts. Thus, it is important to advance in the search for tools that are preferably free and open access that allow teachers to create their own games or edit others created by third parties, based on profiles with different degrees of programming knowledge. This work presents the results obtained from the search, selection and analysis of tools, including web platforms, software applications, and / or frameworks, which allow the creation of serious games, particularly those considered mobile, and which include interactions using augmented reality through QR codes and / or user location, by users with different technical profiles.
\end{abstract}

Keywords: Serious Games, Authoring Tools, Frameworks, Augmented Reality, M-Learning.

\section{Introduction}

Michel \& Chen [1] define serious game (SG) as a way of combining video games and education, where the main objective is education (in any of its forms), and whose main components are: objectives, rules, challenges and interaction. SGs enable another mechanism to carry out teaching and learning, at the same time that it extends the training objectives and generates not only conditions for the player (student) to learn but also to apply and demonstrate what has been learned [1]. On the other hand, a mobile serious game (MSG) is a SG that can be executed on a mobile device such as cell phones or tablets or laptops, providing the player with the possibility of playing at any time and place, that is, making possible the generation of less rigid, personalized and ubiquitous learning environments [2,3]. In addition, the common elements of these types of devices such as: cameras, gyroscopes, etc., give rise to the use of emerging technologies such as augmented reality (AR), which allows enriching a physical context with virtual information. AR is characterized by: (a) a combination

\footnotetext{
${ }^{1}$ Corresponding author
} 
of virtual and real objects in a real environment, (b) users interacting in real time, and (c) an alignment between real and virtual objects [4]. There are different levels of AR, depending on the element that is used as the trigger for it. Thus, level 0 uses QR codes that only make it possible to link other content without any type of interaction or monitoring, level 1 uses markers (quadrangular black and white images with schematic drawings) that allow recognition of 2D patterns and 3D objects. Level 2 includes the recognition of images or objects and / or the positioning of the user giving rise to other types of interactions and the superposition of virtual elements in the captured physical world, and in the last level special devices such as AR lenses are used or others, which allows a more complete integration between the physical and virtual worlds and thus the experiences that can be generated are more immersive and personalized [5]. Regarding to its potential in the educational context, AR allows incorporating multimedia into the teaching-learning process, increasing the richness of the physical context and thus, innovating in teaching practice from the design of educational activities that contribute to the understanding of abstract concepts, of spatiality, student motivation and discovery-based learning, among others [3,5,6,7]. Hence, the combination of AR and mobile devices together with the characteristics of the games allow an instructional design that can help to achieve both affective and cognitive learning outcomes $[8,9]$.

This article is an extension of a previous work [31] in which different tools that can assist teachers with different levels of programming skills to produce their own serious games were analyzed. This new version extends the analysis with new tools that are considered, and it offers a richer discussion.

\subsection{Serious Games Development}

SGs development requires matching instructional design (ID) with game design (game characteristics, mechanics, and playability), thus advancing in the development of a SG requires knowledge of game design, learning theories and mastery of the content to be addressed with it. By the ID, it is possible to define the contents, the skills to be developed, the strategies that will be used to offer the contents and the evaluation mechanisms, all based on the needs of the students, their characteristics and the learning context of application [10]. However, although teachers have expertise in ID, in many cases they do not have the technical knowledge, particularly in programming, to allow them to advance in the development of a SG tailored to the context of their teaching practice. At this point, in the literature $[11,12,13,14,15]$ on the subject some possibilities appear through the so-called authoring tools (AT) and also frameworks that can assist in the design and development process of SGs with little or no programming knowledge.

The term authoring tool (AT) is associated with the idea of software that enables the creation and editing of learning content in multimedia format, so that it can be used in teaching and learning proposals in different media, giving rise to processes of e-learning and m-learning. In this sense, an AT is a software that facilitates the production of applications, which can be used by profiles that do not necessarily have technical knowledge. So, the software will be equipped with a set of functionalities 
and characteristics (friendly interfaces, templates or models, tutoring systems, interoperability with other resources, among others) that allow progress in this sense $[16,18]$.

From the point of view of software engineering [19], a framework represents a skeletal abstraction of solutions to a series of similar problems. In a framework, the steps or stages to follow to implement the solution are described without going into details about the activities that will be carried out in each of the steps. In the specific case of video game development, frameworks allow, with minimal or in some cases without programming knowledge, to accelerate the development process by offering predefined solutions with extension and / or customization possibilities. There are frameworks such as the case of Construct2, which use the drag-and-drop system allowing to create the game logic through pre-built scripts that are associated with the elements of the game that is being built visually. Beyond ease of use, a desirable feature of a framework for SG development is, as Paiva [21] points out, the possibility of changing the (learning) content by re-using the structure of the game, without having to start from scratch.

This work presents a list of ATs and frameworks collected through a bibliographic review process, as well as the criteria established for their evaluation. Then the results achieved with the evaluation of those selected are described and, finally, a discussion and the conclusions reached are presented along with future work. It is important to highlight that this work was carried out in the context of a research project (PIUNRN-40C-750), accredited and funded by the National University of Río Negro (UNRN). The project seeks to generate knowledge about the design, development and application of mobile educational games with augmented reality, in teaching and learning context of medium and higher level of the UNRN.

\section{Authoring Tools and Frameworks Selection}

In the research project mentioned in the previous section, a bibliography review was carried out with the intention of recovering authoring tools and frameworks that can be used for the development of MSGs, in particular those that allow including interactions using AR (where the trigger elements are QR codes and / or the geographic location of the player). The review was limited to the period 2015-2019 and was focused to answer the following questions:

- What technological infrastructure is necessary for its use?

- Do you require programming knowledge? What level?

- What types of games can be built with these tools?

- What level of AR can be implemented?

From this review process, the tools presented in Table 1 were collected, and they have been categorized according to their type (AT or Framework), access form, platform to which the developed game can be exported, type of element used to activate AR, type of activities that can be included in the game using AR (ARAT), the language in which the tool is available, and finally the country of origin. 
Table 1. ATs and Frameworks collected.

\begin{tabular}{|c|c|c|c|c|c|c|}
\hline & Access & Platform & AR trigger & ARAT & Language & Country \\
\hline ARIS [19] & Free (open source) & Mobile (iOS) & $\begin{array}{l}\text { QR } \\
\text { GPS }\end{array}$ & $\begin{array}{l}\text { Interactive } \\
\text { Puzzles }\end{array}$ & English & United States \\
\hline ARLEARN [20] & Free (open source) & Mobile (Android) & GPS & $\begin{array}{l}\text { Interactive } \\
\text { Puzzles }\end{array}$ & English & $\begin{array}{l}\text { The Nether- } \\
\text { lands }\end{array}$ \\
\hline I_learnTest[21] & $\begin{array}{l}\text { Free. User register } \\
\text { required }\end{array}$ & Web & No available & $\begin{array}{l}\text { Quizzes } \\
\text { Association }\end{array}$ & English & Portugal \\
\hline FJSU[22] & Free & $\begin{array}{l}\text { Mobile (Android, } \\
\text { iOS) }\end{array}$ & $\begin{array}{l}\text { No available in } \\
\text { the actual ver- } \\
\text { sion. }\end{array}$ & $\begin{array}{l}\text { Adaptive games, } \\
\text { shooters, RPG } \\
\text { Puzzles }\end{array}$ & Portuguese & Brazil \\
\hline MAGIS[23] & Free & $\begin{array}{l}\text { Mobile ( Android, } \\
\text { iOS) }\end{array}$ & $\begin{array}{l}\text { Fiducially } \\
\text { markers, } \\
\text { GPS }\end{array}$ & $\begin{array}{l}\text { Adventure } \\
\text { Interactive } \\
\text { Puzzles }\end{array}$ & English & Philippines \\
\hline MOLE[11] & Prototype & $\begin{array}{l}\text { Mobile ( Android, } \\
\text { iOS) }\end{array}$ & QR & $\begin{array}{l}\text { Interactive tours } \\
\text { Puzzles }\end{array}$ & Spanish & Argentine \\
\hline $\begin{array}{l}\text { SG Generator } \\
\text { from a base pro- } \\
\text { ject in HTML5 } \\
{[30]}\end{array}$ & Prototype & Multi-device & $\begin{array}{l}\text { Fiducially } \\
\text { markers, images }\end{array}$ & $\begin{array}{l}\text { Rules Games, } \\
\text { Memory Games }\end{array}$ & Spanish & Mexico \\
\hline TaleBlazer [29] & $\begin{array}{l}\text { Free. User register } \\
\text { required }\end{array}$ & $\begin{array}{l}\text { Mobile (Android, } \\
\text { iOS) }\end{array}$ & GPS & Interactive tours & English & United States \\
\hline U-Adventure[24] & Free & $\begin{array}{l}\text { Mobile ( Android, } \\
\text { iOS), Console }\end{array}$ & $\begin{array}{l}\text { GPS } \\
\text { QR }\end{array}$ & $\begin{array}{l}\text { Adventures } \\
\text { Interactive } \\
\text { Puzzles }\end{array}$ & Spanish & Spain \\
\hline VEDILS[13] & $\begin{array}{l}\text { Free. User register } \\
\text { required }\end{array}$ & Mobile (Android) & $\begin{array}{l}\text { Images, Fiduci- } \\
\text { ally markers, } \\
\text { text }\end{array}$ & $\begin{array}{l}\text { Interactive } \\
\text { Puzzles }\end{array}$ & $\begin{array}{l}\text { English } \\
\text { Spanish }\end{array}$ & / Spain \\
\hline
\end{tabular}

The selection presents on Table 1 was filtered, taking into account the following criteria: free access, possibility of exporting the game to be developed to mobile devices with Android operating system, possibility of including activities with augmented reality using QR codes and / or user location. Finally, it was important to take into account the context of application (UNRN), the possibility of using the tool in Spanish language and / or in a visually way. This reduced the possibilities to the following ATs: MOLE [11], SG Generator [30], U-Adventure [23], TaleBlazer [29], VEDILS [13]. However the first two were discarded because at the time of the evaluation, the tools were still in the version of prototype. On the other hand, in the case of [30] although the tool is presented as a possibility to produce multi-device SG that include AR interactions, it requires technical profiles with knowledge in HTML 5 to specify the SG structure. In the case of frameworks, iLearnTest [21] and FSJU [22] have been discarded for not presenting support for the development of games that include interactions with AR. 


\subsection{Evaluation Criteria}

For the evaluation of ATs, the criteria established in other investigations [15, 25, 26] have been followed as well as others established by the authors of this work have also been incorporated. The contributions of [15], allow to evaluate the characteristics of the authoring tools for the development of educational materials that include augmented reality. In other work [25], it is proposed to carry out the evaluation of authoring tools, from the perspective called Critical Success Factor (CSF), analysing factors such as: infrastructure (technological requirements), user (levels, skills and knowledge) and community (of practice), and other aspects such as learning strategies and styles, teaching methods, social presence (interaction, engagement and realism), the degree of commitment generated by the developed product and the fun provided both from the point of view of the person who is carrying out the design and the end user (in this context teachers and students). Based on this, Table 2 presents the evaluation criteria used to analyse the authoring tools and frameworks selected for this study.

Table 2. Evaluation Criteria

\begin{tabular}{|c|c|c|}
\hline Edition Tool & Name & \\
\hline \multicolumn{2}{|c|}{ Analysis Criteria (ACX) } & Detail \\
\hline $\mathrm{ACx} 0$ & License & Cost of access and use of the tool \\
\hline $\mathrm{ACx} 1$ & Technical Requirements & Technical requirements (hardware, software, connectivity) required by the tool \\
\hline $\mathrm{ACx} 2$ & $\begin{array}{l}\text { Shared and collaborative } \\
\text { Edition }\end{array}$ & It is possible to edit the game in a shared / collaborative way \\
\hline $\mathrm{ACx} 3$ & User Profile & Digital skills required to use the tool \\
\hline $\mathrm{ACx} 4$ & Templates & $\begin{array}{l}\text { Templates or models provided by the tool for the generation of games based on } \\
\text { them. }\end{array}$ \\
\hline $\mathrm{ACx} 5$ & Games Types & Games types that could be generated by the tool \\
\hline ACx6 & AR level supported & QR, fiducially markers, user location, images \\
\hline $\mathrm{ACx} 7$ & $\begin{array}{l}\text { Augmented information } \\
\text { supported }\end{array}$ & Supported augmented information types (images, videos, audio, 3D objects, etc.) \\
\hline $\mathrm{ACx} 8$ & Accessibility & The tool enables the development of games that can be considered accessible \\
\hline $\mathrm{ACx} 9$ & Content distribution & Forms provided by the tool for the distribution of the developed game \\
\hline $\mathrm{ACx} 10$ & Analytics & $\begin{array}{l}\text { The tool allows to collect and record information about player interactions during } \\
\text { the execution game }\end{array}$ \\
\hline
\end{tabular}

\subsection{Analysis and discussion of the selected ATs and Frameworks}

The results of the analysis are described below.

U-Adventure. It is a SGs editor that is distributed and it works as an extension of the Unity game engine, and according to its creators, the e-UCM Research Group of the Complutense University of Madrid, allows the production of games to user profiles that do not necessarily have programming knowledge. The tool is built on the basis of a previous version called e-Adventure [27]. So U-Adventure seeks to solve problems of its obsolescence previous version, as well as to open the possibility to the 
generation of multiplatform games [14]. Among the potentialities of U-Adventure, the potential to include in the game interactions using AR both outdoor, through user location and indoor using QR codes as triggers stands out (this last option was part of the e-adventure version). Likewise, it is possible to define on which game events it collects information during its execution, and then carry out an analysis of this as part of the learning evaluation process. Regarding the generation of games for mobile devices, although programming knowledge is not required, the process of exporting projects to the Android operating system is not transparent for the user, since it requires the installation and configuration of Android Studio. At this point, it is observed that although the tool has the desirable features for an AT, it is necessary to have different user profiles during the MSG production process. Table 3 presents the results of the analysis of the tool based on the established criteria.

Table 3. U-Adventure analysis based on Table 2 criteria

\begin{tabular}{|c|c|}
\hline Edition Tool & U-Adventure \\
\hline Analysis Criteria (ACx) & Details \\
\hline $\mathrm{ACx} 0$ & $\begin{array}{l}\text { Download, installation and free use from https://github.com/e-ucm/uAdventure. No user registration } \\
\text { required }\end{array}$ \\
\hline ACx1 & Requires the Unity game development engine (version 2017.3) installed \\
\hline $\mathrm{ACx} 2$ & No shared edition allowed \\
\hline $\mathrm{ACx} 3$ & $\begin{array}{l}\text { Although it does not require programming knowledge to use the tool, it is necessary to have technical } \\
\text { knowledge on how to link the U-Adventure with the Unity engine and it is also necessary to know how } \\
\text { to install and configure Android Studio to export projects in Android format. }\end{array}$ \\
\hline $\mathrm{ACx} 4$ & $\begin{array}{l}\text { A user manual and an installation guide are available through the site https://github.com/e- } \\
\text { ucm/uAdventure, which is currently in English. }\end{array}$ \\
\hline ACx 5 & Templates not available \\
\hline ACx6 & Classical adventures \\
\hline $\mathrm{ACx} 7$ & QR, user location \\
\hline $\mathrm{ACx} 8$ & Images (jpg y png), videos( mp4), audio (mp3), web page links \\
\hline $\mathrm{ACx} 9$ & The tool allows to include text and audio for greater accessibility in the development of projects. \\
\hline $\mathrm{ACx} 10$ & $\begin{array}{l}\text { Analytics are integrated into the tool through the Experience API (xAPI), allowing its use both online } \\
\text { and offline [27]. It has a specific editor to select the events to be recorded. }\end{array}$ \\
\hline
\end{tabular}

TaleBlazer. It is an online and free platform accessible through any browser by http://taleblazer.org/. It allows the development of educational games that include AR interactions using the user's location both outdoors and indoors. The platform was developed by MIT under the Scheller Teacher Education Program and has a game editor that uses a block-based visual scripting language, similar to the Scratch language. The TaleBlazer editor allows the user to create a game from scratch or remix a game already created by the author himself or others.

A game developed with TaleBlazer involves the following elements: agents (characters or objects that the player can interact with during the game execution), regions (real-world locations where the game can be played), scenarios (allows generate dif- 
ferent versions of the game based on the starting point selected by the player at the start) and roles (refers to the character a player plays during the game execution). To design the game's elements, the editor consists of 6 tabs: map, agents, player, world, configuration and beacons, through which the game is configured and built. It is important to note that the current version is available only in English language.

Once a game is created, it is stored in the cloud, and a code is generated that makes it accessible to download and play from the TaleBlazer mobile application. This application is available for mobile devices with operating system like Android 4.0 or higher, and Ios 6.0 or higher. The platform has an emulator option, however in the current version it is not enabled, so the developer can only test a game through the mobile application.

An interesting aspect of the platform is the possibility of generating information about the game regarding its recipients (age range), the type of difficulty involved and the physical space that it intends to travel. This information is presented when downloading the game from the mobile application.

Through the mobile application it is possible to view other games developed with TaleBlazer that are in locations close to the user, making it a very interesting possibility to share the productions of a work team. Regarding the possibility of collecting and retrieving information about the player's interactions during the game, the functionality is only available for special users (officially featured organizations).

Table 4. TaleBlazer analysis based on Table 2 information

\begin{tabular}{ll}
\hline Edition Tool & TaleBlazer \\
\hline Analysis Criteria (ACx) & Details \\
ACx0 & Open-source, free, cloud-based platform. It can be accessible at http://taleblazer.org/. \\
ACx1 & Internet connection. User register \\
ACx2 & Shared edition not allowed \\
ACx3 & Block programming knowledge required \\
ACx4 & Allow create a game from scratch or remix games already created by the author himself or others. It \\
& also has detailed documentation about the creation of different types of games \\
ACx5 & Location based narratives \\
ACx6 & Location outdoor e indoor \\
ACx7 & Image(jpg, png, jpeg, gif), audio ( mp3, wma, m4a, wav, 3gp) and links (web pages or e-mail ad- \\
& dresses) \\
ACx8 & It does not present specific functionality \\
ACx9 & Through code generation. It is transparent by the game developer \\
ACx10 & Only available for special users (officially featured organizations) \\
\hline
\end{tabular}

VEDILS. It was developed at the University of Cádiz (Spain), and its authors [13] define it as a visual environment that allows the design of interactive learning scenarios, in which it is possible to include technologies such as AR among others. VEDILS is based on MIT's App2Inventor development environment and enables the production of augmented content for mobile devices (cell phones and tablets), through a cloud platform, after registration and authorization for use. The tool, which is current- 
ly in version 1.6, is made up of two parts: one where you work on the design of the application to be developed, and another called blocks where it is possible to define the logic of the application using a visual language. At this point, the user of the tool must have knowledge of programming using blocks, as indicated in other investigations [11]. VEDILS has a component called ActivityTracker that makes it possible to collect information on the interactions that occur as part of the game execution, although it must be taken into account that they are registered and processed using the Google Fusion Tables and MongoDB services. Although using this functionality may not be easy for a novel user, VEDILS offers videos and tutorials that can accompany the component configuration process, as well as how to carry out the information analysis process. Regarding the export of the project, it is transparent for the user and can choose between exporting the project as APK (download it on the computer) and then distribute it in the way that is convenient, or generate a QR code to access it, in this case the code will last 2 hours. On the other hand, it is advisable to download the generated projects since they can be removed from the platform for maintenance reasons.

Tabla 5. VEDILS analysis based on Table 2 criteria

\begin{tabular}{ll}
\hline Edition Tool & VEDILS \\
\hline Analysis Criteria (ACx) & Details \\
ACx0 & Free cloud-based platform \\
ACx1 & Internet connection. User registration required \\
ACx2 & Not available \\
ACx3 & Not programming knowledge required for interface design, but it is necessary have block programming \\
& knowledge for define the logic interaction between game elements [11]. \\
ACx4 & Has many tutorials and step-by-step explanations of applications developed with the tool \\
ACx5 & It is possible import others games (.aia) for use in a new one \\
ACx6 & Puzzle \\
ACx7 & QR, location, text and image recognition \\
ACx8 & Images (.png and .jpg), videos( mp4), audio (mp3), 3D models ( obj, 3ds, mds) \\
ACx9 & Allow include text and audio for a greater accessibility in the game \\
ACx10 & Allow collect and register information on player interactions during the game execution. To do so, use a \\
& non-proprietary service (Google Fusion Tables). Use this functionality maybe not be easy for a novel \\
& user. \\
\hline
\end{tabular}

MAGIS. It is a framework designed and created by a group of researchers from the Ateneo de Manila University in Philippines. The framework is an extension of the Unity engine and, seeks to simplify the design of narrative-based games that use the player's location, such as historical or museum tours. [23] Game development using MAGIS implies the creation of scenes where for each one of the objects included in it, a script is generated in the form of a script based on the framework's own commands (and not in the C\# language) and with the format TSV (Tab Separated Values) and the extension .txt. On this point, as the authors themselves point out, creating this type of files manually can be complex and prone to errors, and to avoid this they have 
developed a free access AT, which tries to automate the task, however it presents an interface that it's not visually friendly, which can be daunting specially for an inexperienced user. Likewise, the generation of fiducial markers that can be used to activate AR must be generated with other applications such as Vuforia. Regarding the possibility of recording and processing the information that occurs as part of the player's interactions, its authors indicate that it has an analysis subsystem that can be activated in two ways: through the events that take place during the game (i.e., scanning a scoreboard) or through the scripts that define the game logic using the specific @ analytics commands. The game stores the collected data in cache and then sends it to the analysis server, where it is recorded for later viewing and analysis. At this point, the MAGIS user guide does not provide specific information.

Table 6. MAGIS analysis based on Table 2 criteria

\begin{tabular}{ll}
\hline Edition Tool & MAGIS \\
\hline Analysis Criteria (CAX) & Details \\
ACx0 & Free under GNU license \\
ACx1 & Unity 5 (2016) \\
ACx2 & Not available \\
ACx3 & Knowledge programming required \\
ACx4 & Has a framework user's guide and an scripting guide on creating game engine scripts using the AT \\
ACx5 & Location based adventures \\
ACx6 & Markers, Location \\
ACx7 & Images (png), audio (ogg), 3D models (FBX) \\
ACx8 & Audio could be used as a resource to provide accessibility \\
ACx9 & Using the functionalities provided by Unity personal version it can be distributed as APK \\
ACx10 & It has an analysis subsystem, but its use is not specified in the user manual \\
\hline
\end{tabular}

\section{Conclusion and perspectives}

The possibilities offered by the MSGs into learning activities are varied and allow to attend to different aspects: cognitive, emotional and motivational among others, and in the particular case of those games that include interactions using AR, these possibilities allow to take advantage of the physical environment in which they are carried out, giving rise to contextualized learning and discovery. However, existing games are not always adapted to the needs of the application context, so there is a need for tools that enable teachers with different levels of technical knowledge to advance in the development and subsequent re-use of SGs. In the case of the tools that were analyzed in the previous section, TaleBlazer and VEDILS are presented as an alternative that allow to edit from the cloud, from scratch or based on other games, and where the distribution of the game developed is carried out in a transparent way for the user, however it will be necessary to have knowledge of programming using blocks. About TaleBlazer, although it presents a more limited set of supported augmented information, it has tutorials that not only facilitate and guide the use of the platform, but 
also allow to understand the process of design a serious game. Here, an obstacle to overcome, may be in some cases the AT language.

In the case of U-Adventure and MAGIS, both are presented as alternatives for user profiles with technical knowledge (configuration in the case of the first and programming in the case of the second) that allow them to advance with the use of a generation game engine like Unity. In the case of MAGIS, the language used to script the game scenes can be confusing for a novel user.

Regarding the possibility of having specific functionalities to carry out learning analytics about the interactions that take place during the game execution, any of the AT and frameworks analysed, requires an extra effort by the user, although in the case of U-Adventure having a specific editor integrated into the tool, may be of support for the process.

Any of the cases analyzed requires an extra effort by the user, to use the functionalities that allow to retrieve information about the interactions that occur during the game execution (learning analytics), but in the case of U-Adventure, having a specific editor integrated into the tool, may be of support for the process.

In conclusion, so that teachers can advance in the production of MSGs that include interactions using AR, it will be necessary not only to have knowledge of instructional design but also technical knowledge that allows to maximize the use of tools (whether ATs or frameworks) and put them at the service of the pedagogical proposal. Although the tools analyzed in this work, improve the possibilities of intervention for development of MSGs by non-technical users, we agree with recent research [29] that points out the need to advance in the development of tools that improve usability. At this point it is fundamental the access and use of the tools do not became in a technical problem.

It is proposed as future work, to approach the design and production of a MSG with one of these tools, analyzing the roles and interventions of a team in which teachers with different technical profiles have an active participation in this process.

\section{References}

1. Michael, D. R., \& Chen, S. L. (2005). Serious games: Games that educate, train, and inform. Muska \& Lipman/Premier-Trade.

2. Demir, K., \& Akpinar, E. (2018). The Effect of Mobile Learning Applications on Students' Academic Achievement and Attitudes toward Mobile Learning. Malaysian Online Journal of Educational Technology, 6(2), 48-59.

3. De la Torre Cantero, J., Martin-Dorta, N., Pérez, J. L. S., Carrera, C. C., \& González, M. C. (2015). Entorno de aprendizaje ubicuo con realidad aumentada y tabletas para estimular la comprensión del espacio tridimensional. Revista de Educación a Distancia, (37).

4. Azuma, R., Baillot, Y., Behringer, R., Feiner, S., Julier, S., \& MacIntyre, B. (2001). Recent advances in augmented reality. Naval Research Lab Washington Dc.

5. Melo, I. M. (2018). Realidad aumentada y aplicaciones. TIA , 6(1), pp. 28-35.

6. Fonseca Escudero, D., Redondo Domínguez, E., \& Valls, F. (2016). Motivación y mejora académica utilizando realidad aumentada para el estudio de modelos tridimensionales ar- 
quitectónicos. Teoría de la Educación. Educación y Cultura en la Sociedad de la Información, 17(1).

7. Salazar Mesía, N., Gorga, G., Sanz, C. V. (2015). EPRA: Herramienta para la enseñanza de conceptos básicos de programación utilizando realidad aumentada. In X Congreso sobre Tecnología en Educación \& Educación en Tecnología (TE \& ET)(Corrientes, 2015).

8. Schmitz, B., Klemke, R., \& Specht, M. (2013). Effects of mobile gaming patterns on learning outcomes: a literature review.

9. Chang, C. Y., \& Hwang, G. J. (2019). Trends in digital game-based learning in the mobile era: a systematic review of journal publications from 2007 to 2016. International Journal of Mobile Learning and Organisation, 13(1), 68-90.

10. Fernández-Robles, J. L., \& Hernández-Gallardo, S. C. Diseño instruccional de un juego serio que facilite a niños de tercer grado de primaria el ejercicio de operaciones matemáticas básicas

11. Dal Bianco, P. A., Mozzon Corporaal, F., Lliteras, A. B., Grigera, J., \& Gordillo, S. E. (2019). MoLE: A web authoring tool for building mobile learning experiences. In XXV Congreso Argentino de Ciencias de la Computación (CACIC 2019, Universidad Nacional de Río Cuarto)

12. Firssova, Olga; Vogel, Cathrin; Brouns, Francis; Diegel, Noëlle; Forsman, Panu; Stracke, Christian M. (2019). Designing for Virtual Mobility : Potentials and Caveats. In Fessl, Angela; Zdolšek Draksler, Tanja (Eds.) EC-TEL Practitioner Proceedings 2019 : 14th European Conference on Technology Enhanced Learning, Delft, Netherlands, September 1619, 2019., CEUR Workshop Proceedings, 2437. Springer International Publishing. http://ceur-ws.org/Vol-2437/paper4.pdf

13. Mota, J.M., and Ruiz-Rube, I.. (2017). VEDILS: a toolkit for developing Android mobile apps supporting mobile analytics. Seventh European Business Intelligence \& Big Data Summer School (eBISS 2017)

14. Perez-Colado, I. J., Perez-Colado, V. M., Martínez-Ortiz, I., Freire-Moran, M., \& Fernández-Manjón, B. (2017, April). UAdventure: The eAdventure reboot: Combining the experience of commercial gaming tools and tailored educational tools. In 2017 IEEE Global Engineering Education Conference (EDUCON) (pp. 1755-1762). IEEE.

15. Moralejo, L. (2014). Análisis comparativo de herramientas de autor para la creación de actividades de realidad aumentada (Doctoral dissertation, Facultad de Informática).

16. Cubillo, J. (2014). ARLE: una herramienta de autor para entornos de aprendizaje de realidad aumentada (Doctoral dissertation, UNED. Universidad Nacional de Educación a Distancia (España))

17. Karoui, A., Marfisi-Schottman, I., \& George, S. (2016, December). Mobile learning game authoring tools: assessment, synthesis and proposals. In International Conference on Games and Learning Alliance (pp. 281-291). Springer, Cham.

18. Mnkandla, E. (2009). About software engineering frameworks and methodologies. In AFRICON 2009 (pp. 1-5). IEEE.

19. https://arisgames.org/editor/

20. http://portal.ou.nl/web/topic-mobile-learning/home/-/wiki/Main/ARLearn

21. Paiva, A. C., Flores, N. H., Barbosa, A. G., \& Ribeiro, T. P. (2016). iLearnTestframework for educational games. Procedia-Social and Behavioral Sciences, 228, 443-448.

22. Silveira Júnior, G. D. (2019). FJSU: Um Framework para o desenvolvimento de jogos sérios ubíquos.

23. Vidal Jr, E. C. E., Ty, J. F., Caluya, N. R., \& Rodrigo, M. M. T. (2019). MAGIS: mobile augmented-reality games for instructional support. Interactive Learning Environments, 27(7), 895-907. 
24. Pérez-Colado, V. M., Pérez-Colado, I. J., Freire-Morán, M., Martínez-Ortiz, I., \& Fernández-Manjón, B. (2019). uAdventure: Simplifying Narrative Serious Games Development. In 2019 IEEE 19th International Conference on Advanced Learning Technologies (ICALT) (Vol. 2161, pp. 119-123). IEEE.

25. Teoh, K.K. \& Sliuzas, R. (2016). Multimedia development of online literacy objects: An evaluation of authoring tools for novice authors. In H. Hamerton and C. Fraser (Eds.), Te tipuranga - Growing capability: Proceedings of the 2015 National Tertiary Learning and Teaching Conference (pp. 70-76). Tauranga, New Zealand: Bay of Plenty Polytechnic.

26. Christopoulou, E., \& Xinogalos, S. (2017). Overview and comparative analysis of game engines for desktop and mobile devices.

27. http://e-adventure.e-ucm.es/

28. Ivan Perez-Colado, Víctor Manuel Pérez-Colado, Manuel Freire, Iván Martínez-Ortiz, Baltasar Fernández-Manjón (2017): Integrating learning analytics into a game authoring tool. ICWL 2017: 16th International Conference on Web-based Learning. Cape Town, South Africa, 20 September -22 September 2017

29. Ahmad, A., Law, E. L., \& Moseley, A. (2020). Integrating Instructional Design Principles in Serious Games Authoring Tools: Insights from Systematic Literature Review. In Proceedings of the 11th Nordic Conference on Human-Computer Interaction: Shaping Experiences, Shaping Society (pp. 1-12).

30. García Aguilar, José Gregorio. (2019). Desarrollo de un generador de juegos serios educativos multi-dispositivo con implementación de realidad aumentada (Doctoral dissertation).

31. Lovos, E., Basciano, I., Gil, E. \& Sanz, C. V. (2020). La Producción de Juegos Serios Móviles. Posibilidades y Desafíos para el Docente de Nivel Superior. In Actas del Congreso Argentino de Ciencias de la Computación (pp. 144-153). Universidad Nacional de La Matanza 